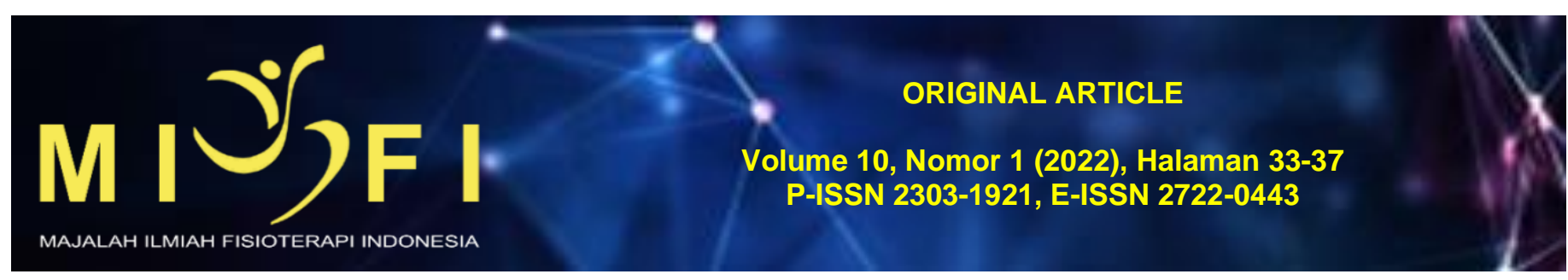

\title{
HUBUNGAN ANTARA KEKUATAN OTOT LENGAN DAN KETEPATAN MEMANAH RONDE NASIONAL PADA ATLET PANAHAN DI DENPASAR DAN BADUNG
}

\section{Made Rania Deviyanti ${ }^{*}$, Made Hendra Satria Nugraha ${ }^{2}$, I Made Muliarta ${ }^{3}$, I Dewa Ayu Inten Dwi Primayanti ${ }^{4}$}

\author{
${ }^{1}$ Program Studi Sarjana Fisioterapi dan Profesi Fisioterapi, Fakultas Kedokteran Universitas Udayana, Denpasar, Bali \\ ${ }^{2}$ Departemen Fisioterapi, Fakultas Kedokteran, Universitas Udayana, Denpasar, Bali \\ ${ }^{3,4}$ Departemen IImu Faal, Fakultas Kedokteran, Universitas Udayana, Denpasar, Bali \\ *Koresponden: raniadeviyanti@gmail.com
}

Diajukan: 24 Juni 2021 | Diterima: 26 Juni 2021 | Diterbitkan: 25 Januari 2022

DOI: https://doi.org/10.24843/MIFl.2022.v10.i01.p07

\begin{abstract}
ABSTRAK
Pendahuluan: Panahan merupakan suatu keterampilan memakai busur serta panah, olahraga ini anak panah akan dilepaskan melewati jarak untuk menuju pada sasaran tembak. Faktor untuk meningkatkan keakurasian memanah yaitu kekuatan otot lengan. Kekuatan dapat meningkatkan komponen seperti kelincahan, kecepatan serta ketepatan. kekuatan merupakan satu kesatuan dengan olahraga panahan yang tidak dapat dipisahkan dalam meningkatkan prestasi atlet. Tujuan penelitian ini untuk mengetahui hubungan kekuatan otot lengan dengan ketepatan memanah ronde nasional pada atlet panahan di Denpasar dan Badung.

Metode: Penelitian ini menggunakan studi observasional dengan rancangan cross sectional dan teknik consecutive sampling untuk pengambilan sampel. Penelitian dilaksanakan di Kota Denpasar dan Badung pada Februari - Maret 2021. Jumlah subjek pada penelitian ini adalah 65 subjek yang disesuaikan dengan kriteria yang sudah ditentukan yaitu inklusi dan eksklusi. Pengumpulan data penelitian dilakukan dengan mengukur kekuatan otot lengan dengan alat pull and push dynamometer serta ketepatan/keakurasian memanah dengan memanah sebanyak 2 sesi dan diambil nilai reratanya.

Hasil: Uji hipotesis pada penelitian ini yaitu Rank Spearman Rho agar dapat menganalisis hubungan antara kekuatan otot lengan dengan ketepatan memanah. Berdasarkan uji analisis Rank Spearman Rho didapatakan nilai signifikan $\mathrm{p}=$ 0,003 dengan koefiien korelasi $r=0,363$.

Simpulan: Hasil penelitian ini dapat disimpulkan bahwa terdapat hubungan yang signifikan dengan korelasi yang lemah dan searah antara kekuatan otot lengan dengan ketepatan memanah ronde nasional pada atlet panahan di Denpasar dan Badung.
\end{abstract}

Kata Kunci: panahan, kekuatan otot lengan, ketepatan memanah

\section{PENDAHULUAN}

Olahraga merupakan suatu kegiatan fisik yang mampu membantu kita dalam meningkatkan kualitas hidup yang lebih baik. Manfaat dari olahraga sendiri adalah untuk menjaga fleksibilitas otot, meningkatkan kinerja otot serta meningkatkan konsentrasi. ${ }^{1}$ Salah satu olahraga yang menggunakan kinerja otot dan konsentrasi yaitu olahraga panahan. Panahan merupakan perpaduan olahraga dengan seni, dikatakan olahraga sebab dalam permainannya menggunakan otot fungsional dan juga memerulakan ketahanan fisik. Dikatakan seni sebab dalam panahan membutuhkan kesabaran serta ketahanan mental. ${ }^{2}$ Prestasi panahan dapat ditingkatkan dengan dukungan sarana dan prasarana yang layak, dan dalam oahraga panahan juga mengharuskan seorang atlet untuk menguasai serta mengerti kemampuan teknik mendasar dari memanah. ${ }^{3}$ Teknik-teknik dasar merupakan faktor terpenting untuk mencapai keberhasilan dalam panahan. Terdapat 9 teknik dasar panahan yang wajib dilaksankan oleh atlet panah, meliputi : Sikap berdiri (stand/ stance), Memasang ekor anak panah (nocking), Mengangkat busur panah dengan lengan lurus (extend), Meregangkan tali busur (drawing), Mencari posisi lengan yang menarik (anchoring), mempertahankan gerak memanah (hold/tighten), membidik (aiming), melepaskan anak panah (release), Menahan gerak memanah (after hold). ${ }^{4}$ Dari hal tersebut yang menjadi tujuan akhir memanah adalah ketepatan memanah. Ketepatan (accuracy) adalah kemampuan seseorang melepaskan panah tepat pada sasaran yang ditembak. ${ }^{5}$ Ketepatan dalam olahraga panahan bisa disebabkan atas beberapa faktor/aspek contohnya kekuatan otot, daya tahan otot, persepsi Kinestetik, konsentrasi, kecemasan, dan metode latihan. ${ }^{6}$

Dalam panahan masalah yang sering terjadi ketika atlet memiliki kekuatan otot lemah adalah saat menarik tali busur, lengan menjadi tidak seimbang serta terlalu cepat melepaskan anak panah. Dengan otot yang lemah tentunya hal tersebut dapat menghambat seseorang dalam melaksanakan aktivitas fungsionalnya. ${ }^{7}$ Menurut penelitian, kemampuan fisik atlet panahan Bali belum mencapai maksimal, hal tersebut yang menyebabkan pencapaian prestasi atlet di kancah nasional maupun internasional belum meningkat. Sehingga kondisi fisik seperti kekuatan otot lengan sangat berperan penting dalam teknik-teknik panahan. ${ }^{8}$ 
Kekuatan otot merupakan suatu kondisi dimana otot atau sekelompok otot mampu menahan serta mengangkat sebuah berat. Kekuatan otot lengan benar-benar memiliki peran utama dalam panahan karena mengarah kepada gerakan drawing (menarik tali busur) saat memanah hingga melepas anak panah. Menurut penelitian, dengan mempunyai kekuatan otot lengan baik seorang pemanah pastinya akan mahir dalam membidik sehingga mengenai face target setepat mungkin untuk mencetak skor tertinggi. ${ }^{9}$ Menurut World Health Organization (WHO) remaja yang memiliki usia dari rentangan 10-19 tahun akan mengalami perubahan fisik, salah satunya adalah kekuatan otot, dimana pada umumnya kekuatan otot sudah mulai terlihat sejak lahir dan akan terus mengalami peningkatan hingga dewasa dimana pada usia 20 sampai 30 tahun. Seiring dengan bertambahnya usia, kekuatan otot akan sedikit demi sedikit mengalami pengurangan. Pada usia 40 tahun kekuatan otot akan mengalami penurunan dan akan semakin cepat mengalami penurunan pada usia 75 tahun keatas. ${ }^{10}$ Dengan kekuatan otot, pemanah mampu mengangkat busur panah setinggi bahu dan melakukan tarikan yang lebih besar pada busur sehingga menghasilkan gerakan yang lebih cepat pada anak panah. ${ }^{9}$

Berdasarkan penjelasan diatas, peneliti tertarik untuk mengetahui hubungan kekuatan otot lengan dengan ketepatan memanah pada ronde nasional. Ronde nasional terdiri atas beberapa ronde, salah satunya ronde nasional tunggal, dimana seorang pemanah dapat membidik sebanyak 36 anak panah disetiap jarak yang ditentukan. Jarak yang diperlombakan itu 50 meter, 40 meter, 30 meter. ${ }^{11}$

\section{METODE}

Penelitian cross sectional ini menggunakan 65 subjek remaja putra dan putri yang berumur 10-19 tahun pada beberapa klub panahan di Kota Denpasar dan Badung. Penelitian ini sudah lulus uji kelaikan etik dari Komisi Etik Penelitian (KEP) Fakultas Kedokteran Universitas Udayana/Rumah Sakit Umum Pusat Sanglah Denpasar dengan nomor 1204/UN14.2.2.VII.14/LT/2020. Penelitian dilaksanakan selama 5 hari pada tanggal 5,7,16,18 Februari dan 7 Maret 2021. Subjek dipilih menggunakan teknik consecutive sampling yang sebelumnya sudah memenuhi kriteria inklusi meliputi, berjenis kelamin perempuan dan laki-laki, berumur 10 - 19 tahun, kedatangan latihan yang rutin minimal $75 \%$ selama 2 bulan terakhir, secara sukarela berkenan sebagai subjek dari pertama sampai dipenghujung penelitian dengan menyetujui surat penjelasan dan persetujuan (informed consent) yang telah dipersiapkan oleh peneliti untuk bersedia sebagai subjek dan tidak memenuhi kriteria eksklusi yaitu, mempunyai kejadian patah tulang atau cidera parah pada muskuloskeletal bagian ekstremitas atas serta kriteria drop out diantaranya, subjek tidak datang saat dilaksanakannya penelitian, tidak bersedia mengikuti instruksi penelitian dengan benar.

Kekuatan otot lengan merupakan variabel independen dalam penelitian ini, ketepatan memanah merupakan variabel dependen sedangkan untuk variabel kontrol adalah usia. Kekuatan otot lengan dites dengan alat pull and push dynamometer dengan satuan $(\mathrm{kg})$ dan memiliki validitas sebesar 0,866 sedangkan untuk reliabilitas sebesar $0,938^{12}$, dimana semakin besar angka yang didapat maka akan semakin baik kekuatan otot. Sedangkan ketepatan memanah dapat diukur menggunakan tes ketepatan dengan menembakkan anak panah pada 2 sesi dengan setiap sesi berisi 6 rambahan dan setiap rambahannnya atlet panah harus menembakan anak panah sebesar 6 buah selama 4 menit Sehingga sebanyak 72 panah yang akan ditembakkan pada sasaran dalam jarak 30 meter dengan validitas sebesar 0,908 dan realibilitas sebesar $0,738 .{ }^{13}$ Hasil dari akurasi ditentukan dengan hasil jumlah dari kedua sesi kemudian hasil dibagi 72 unutk mengetahui rata-rata setiap anak panahnya, dimana semakin ke dalam anak panah mengenai target face maka skor akan meningkat. Skor tertinggi dari target face adalah 10 yaitu tepat pada tengah-tengah target face dan setiap warna memiliki skor yang berbeda-beda antara lain, 9,8,7,6,5,4,3,2,1.

Data yang sudah terkumpul akan diuji menggunakan Rank Spearman Rho untuk mengetahui hubungan kekuatan otot lengan dengan ketepatan memanah.

\section{HASIL}

Penelitian ini mendata 65 orang atlet dari 5 klub panahan di Denpasar dan Badung dari umur 10-19 tahun. Berikut merupakan tabel hasil dari penelitian ini, pada Tabel 1.

Tabel 1. Distribusi Frekuensi Karakteristik Subjek berdasarkan Jenis Kelamin.

\begin{tabular}{ccc}
\hline Jenis Kelamin & Frekuensi & Persentase (\%) \\
\hline Laki-laki & 33 & 50,8 \\
Perempuan & 32 & 49,2 \\
\hline Total & 65 & 100 \\
\hline
\end{tabular}

Pada Tabel 1. diatas menunjukan subjek yang berjenis kelamin laki- laki sebanyak 33 orang $(50,8 \%)$ sedangkan yang berjenis kelamin perempuan sebanyak 32 orang $(49,2 \%)$.

Tabel 2. Distribusi Frekuensi Karakteristik Subjek berdasarkan Usia, Kekuatan Otot Lengan dan Ketepatan Memanah

\begin{tabular}{ccccc}
\hline & Rata-rata \pm Simpang Baku & Minimum & Maksimum & Modus \\
\hline Usia & $13,63 \pm 2,897$ & 10 & 19 & 11 \\
\hline Kekuatan Otot Lengan & $20,46 \pm 9,93$ & 5 & 47 & 21 \\
\hline Ketepatan Memanah & $7,51 \pm 1,13$ & 4,16 & 9,43 & 8,43 \\
\hline
\end{tabular}

Berdasarkan Tabel 2. dapat dilihat rentang usia atlet panahan sesuai dengan kriteria inklusi yaitu 10-19 tahun. Rata-rata usia subjek yang didapatkan adalah 13,63 dengan standar deviasi 2,897. Sedangkan nilai terbanyak dari kekuatan otot lengan sebesar 21 kilogram dan nilai terendah yang diperoleh subjek adalah 5 kilogram sedangkan nilai tertinggi adalah 47 kilogram. Kekuatan otot lengan dapat dites dengan alat Pull and Push Dynamometer. Rata-rata nilai kekuatan otot lengan sebesar 20,46 kilogram dengan standar deviasi 9,93. Kekuatan otot dengan nilai $>24$ untuk perempuan dan >60 untuk laki-laki dikategorikan baik sekali, nilai 20-23 untuk perempuan dan 44-59 untuk laki-laki 
dikategorikan baik, nilai 14-19 untuk perempuan dan 21-43 untuk laki-laki dikategorikan sedang, nilai 11-13 untuk perempuan dan 5-20 untuk laki-laki dikategorikan kurang, dan nilai $<10$ untuk perempuan dan $<4$ untuk laki-laki dikategorikan kurang sekali. ${ }^{14}$

Pada ketepatan memanah Tabel 2. diatas menunjukan bahwa nilai rata-rata poin terbanyak dari ketepatan memanah adalah 8,43 dan nilai rata-rata poin terendah dari ketepatan memanah diperoleh 4,16 poin sedangkan nilai rata-rata poin tertinggi diperoleh 9,43 poin. Nilai rata-rata ketepatan/keakurasian memanah yaitu 7,51 dengan standar deviasi 1,13 .

Tabel 3. Uji Normalitas Kolmogrof- Smirnov

\begin{tabular}{cc}
\hline Variabel & $\mathrm{p}$ \\
\hline Kekuatan Otot Lengan & 0,000 \\
Ketepatan Memanah & 0,001 \\
\hline
\end{tabular}

Berdasarkan Tabel 3. terdapat variabel kekuatan otot lengan yang memiliki $p<0,05(0,000)$ dan variabel ketepatan memanah mempunyai $\mathrm{p}<0,05(0,001)$ yang memiliki arti kedua variabel tersebut berdistribusi tidak normal.

Tabel 4. Hubungan antara Kekuatan Otot Lengan dengan Ketepatan Memanah

\begin{tabular}{ccc}
\hline Korelasi Variabel & Korelasi & $p$ \\
\hline Kekuatan Otot Lengan dengan Ketepatan Memanah & 0,363 & 0,003 \\
\hline
\end{tabular}

Berdasarkan Tabel 4. terdapat hubungan yang signifikan antara kekuatan otot lengan dengan ketepatan memanah, dimana nilai koefisien korelasi sebesar 0,363 dengan nilai $p=0,003(p<0,05)$ dan bernilai positif. Hal ini menunjukan bahwa terdapat hubungan yang lemah, signifikan dan berbanding lurus antara kekuatan otot lengan dengan ketepatan memanah pada atlet panahan di Kota Denpasar dan Badung.

\section{DISKUSI \\ Karakteristik Responden}

Pengambilan data pada penelitian ini dilakukan selama 5 hari di 5 klub panahan yang berada di Kota Denpasar dan Badung. Total jumlah subjeknya yaitu 65 remaja dengan kriteria yang sudah ditentukan yaitu inklusi dan eksklusi. Subjek penelitian memilik rentangan usia 10-19 tahun dengan jumlah terbanyak berusia 11 tahun yaitu sejumlah 11 orang $(16,9 \%)$. Dari 65 orang, subjek laki-laki sebanyak $33(50,8 \%)$ sedangkan subjek perempuan sebanyak 32 $(49,2 \%)$.

Berdasarkan hasil penelitian nilai kekuatan otot lengan subjek memiliki nilai yang sangat beragam. Rentangan nilai kekuatan otot lengan mulai dari 5-47 kilogram dengan rata-rata 20,46. Terdapat 8 subjek yang menarik alat dengan nilai 21 kilogram, dimana itu merupakan nilai kekuatan otot lengan dengan subjek terbanyak. Kekuatan otot merupakan suatu kondisi dimana otot atau sekelompok otot mampu menahan dan mengangkat suatu beban. Menurut penelitian, kekuatan otot lengan memiliki peran penting dalam olahraga panahan dalam melakukan gerakan drawing (menarik tali busur) saat memanah hingga melepaskan anak panah. ${ }^{7}$ Alat untuk mengukur kekuatan otot lengan pada penelitian ini dengan Pull and Push Dynamometer. Pengukuran ini dilakukan dengan subjek berdiri tegak, dengan memposisikan kaki selebar bahu lalu alat dipegang dengan tangan kanan dan kiri didepan dada, posisi pull and push dynamometer dihadapakan ke depan dan posisikan kedua lengan fleksi sejajar dengan bahu. Subjek melakukan gerakan menarik (pull) sekuat-kuatnya dengan perlahan dan badan tetap berdiri tegak.

Berdasarkan hasil penelitian nilai ketepatan memanah subjek memiliki nilai yang beragam, dengan nilai ratarata poin terendah sebesar 4,16 dan nilai rata-rata poin tertinggi sebesar 9,43 poin. Hampir setiap nilai rata-rata poin yang dipaparkan dimiliki oleh satu subjek, namun terdapat beberapa subjek yang memiliki nilai rata-rata poin yang sama. Subjek terbanyak adalah 3 subjek dengan nilai rata-rata poin yang sama yaitu 8,43. Ketepatan (accuracy) adalah kemampuan seseorang melepaskan panah tepat pada sasaran yang ditembak. ${ }^{5}$ Dalam memanah ketepatan merupakan tujuan utama yang harus dicapai seorang atlet dalam olahraga panahan, dimana ketepatan memanah salah satu faktor penting untuk meningkatkan prestasi dari atlet tersebut.

\section{Hubungan Kekuatan Otot Lengan dengan Ketepatan Memanah}

Berdasarkan dari hasil pengujian data dengan menggunakan analisis non parametrik spearman rho (tabel 5.6) ditemukan nilai koefisien korelasi 0,363 dengan hasil $p=0,003(p<0,05)$. Hal ini membuktikan adanya hubungan yang lemah, signifikan, dan berbanding lurus antara kekuatan otot lengan dengan ketepatan memanah pada atlet di Kota Denpasar dan Badung. Hal ini menunjukan semakin baik/tinggi nilai kekuatan otot lengan maka semakin baik/ tinggi juga ketepatan memanah.

Penelitian lain yang mendukung hasil diatas dilaksanakan juga oleh Ilham (2014). Pada penelitiannya membahas tentang hubungan kekuatan otot lengan terhadap ketepatan memanah. Untuk dapat mengukur kekuatan otot lengan pada peneltiian ini dapat digunakan alat Pull and Push Dynamometer dengan hasil yang didapatkan menunjukkan bahwa hubungan antara kekuatan otot lengan terhadap ketepatan memanah memiliki nilai $p=0,012$ $(p<0,05)$ yang artinya terdapat hubungan yang signifikan dengan koefisien korelasi sebesar $0.455 .{ }^{9}$

Kekuatan merupakan suatu komponen yang paling penting dalam menunjang kondisi tubuh, hal ini karena tenaga dari penggerak pada aktivitas tubuh adalah kekuatan. Selain itu yang mampu melindungi otot dari peluang teradinya cedera adalah kekuatan. Kinerja dari otot yang maksimum menyebabkan peningkatan kapasitas kinerja pada orang sehingga mampu mengembangkan kemampuan atlet saat kompetisi. ${ }^{15}$ Kekuatan dapat meningktakan komponen- komponen seperti kelincahan, kecepatan serta ketepatan. Maka dari itu, kekuatan merupakan satu kesatuan dengan olahraga panahan yang tidak dapat dipisahkan. ${ }^{16}$ 
Kekuatan dalam panahan memiliki peranan penting dalam melakukan gerakan melengkungkan/menarik tali busur dengan maksimal untuk dapat melepaskan anak panah ke target face. Menarik merupakan suatu cara pada posisi penjangkaran untuk menggerakan tali busur, lalu merentangkan busur sehingga memperoleh potensi energy dari busur. Pada fase menarik posisi terbaik pemanah adalah dengan menarik tali busur hingga menyentuh bibir, dagu dan hidung, saat menarik tali busur diperlukan tipe kontraksi isotonik yaitu kontraksi isotonik kosentrik, maka dari itu lengan yang memegang busur harus terjaga agar dapat mengatur kekuatan dari setiap tarikan yang dilakukan. Saat melakukan tarikan full (penuh), lengan tersebut yang menggenggam busur diperlukan tipe kontraksi isometric untuk mengunci tarikan busur. Untuk memperoleh tingkat rentangan yang efisien dan aman saat menarik tali busur, maka atlet harus mampu menggunakan otot yang diperlukan saja. Karena jika kecenderungan menggunakan otot yang lebih banyak dapat menyebabkan atlet cepat kelelahan, dapat menyebabkan kemungkinan kesalahan yang besar serta mempersulit dalam mempertahankan rentangan tali busur secara optimal. ${ }^{16}$

Pada posisi berdiri dari menarik tali busur hingga melepaskan anak panah, posisi atlet harus dalam keadaan berdiri tegak dan seimbang, otot-otot yang bekerja saat berdiri antara lain, Otot Erector Spinae, dimana otot ini dapat mempertahankan trunk agar tetap dalam posisi tegak saat melakukan gerakan menaarik serta mempertahankan tarikan busur. Otot Rectus Abdominis, otot ini berperan bersama-sama dengan Otot Erector Spine agar tubuh tetap dalam keadaan tegak atau vertikal. Otot Gluteus Maximus, otot ini digunakan untuk mempertahankan stabilisasi dari panggul pada posisi berdiri selama memanah. Otot Quadricep Femoris, merupakan kelompok otot untuk mempertahankan stabilitas lutut. Otot Tricep Surae, merupakan kelompok otot yang terdiri dari Otot Gastrocnemius dan Otot Soleus untuk mempertahankan stabilitas pergelangan kaki (Ankle). ${ }^{16}$

Otot lengan yang bekerja pada saat memanah terdapat 3 bagian yaitu otot lengan atas seperti otot fleksor seperti Otot Deltoid anterior, Otot Biceps brachi, Otot Brachialis, Otot Coracobrachialis. Selain itu ada otot ekstensor seperti Otot Deltoid posterior, dan Otot Triceps Brachi. Otot lengan bawah seperti Otot ventralis yaitu Otot Pronator Teres, Otot Palmaris Longus, Otot Flexor Digitorum Superficialis, Otot Flexor Carpi Radialis, Otot Flexor Carpi Ulnaris. Otot-otot radialis yaitu Otot Brachioradialis, Otot Extensor Carpi Radialis Longus, Otot Extensor Carpi Radialis Brevis. Otot dorsalis yaitu Otot Extensor Digitorum, Otot Extensor Digiti Minimi, Otot Extensor Carpi Ulnaris, serta otot-otot yang ada ditangan. ${ }^{16}$ Dengan memiliki kerja otot yang maksimal serta kekuatan otot lengan yang baik maka atlet dapat meningktakan ketepatan memanahnya. ${ }^{9}$

Ketepatan adalah kemampuan seseorang yang dapat mengendalikan anak panah sehingga tepat mengenai sasaran. ${ }^{5}$ Sasaran tersebut dapat berupa suatu objek, dalam panahan sasaran yang dicapai adalah face target. Ketepatan dalam memanah akan tercapai jika melalui latihan-latihan yang kontinyu dan sistematis. Pada cabor panahan memiliki teknik basic/dasar dalam permainan memanah, bentuk basic/dasar dari teknik permainan panah itu jika dipantau dari sisi/segi mekanika gerak serta anatomi yang baik/benar, maka akan mendapatkan gerakan memanah yang akurat dan konsisten. ${ }^{9}$

Penelitian serupa juga dilakukan oleh Risman (2016) mengenai hubungan kekuatan otot lengan dengan ketepatan memanah dalam jarak $30 \mathrm{M}$. Hasil menunjukkan bahwa hubungan kekuatan otot lengan terhadap kemampuan memanah memiliki koefisien korelasi yang kuat sebesar 0,806 dengan nilai signifikan 0,000<0,05 dan memberikan koefisien determinasi yaitu 0,650 sehingga dapat diartikan bahwa memiliki pengaruh kekuatan otot lengan terhadap kemampuan dari memanah sebesar 65\% dan sisanya dipengaruhi variabel lain. ${ }^{17}$

\section{SIMPULAN}

Berdasarkan dari hasil penelitian maka dapat disimpulkan bahwa terdapat hubungan yang signifikan dengan korelasi yang lemah dan searah antara kekuatan otot lengan dengan ketepatan memanah ronde nasional pada atlet panahan di Kota Denpasar dan Badung.

\section{DAFTAR PUSTAKA}

1. Kementerian Kesehatan Republik I. Olahraga \& 59 Manfaat Bagi Tubuh [Internet]. 1 Juni 2019.2017. p. https://promkes.kemkes.go.id/?p=7388. Available from: https://promkes.kemkes.go.id/?p=7388

2. Yachsie B. Pengaruh Latihan Dumbell-Thera Band Terhadap Daya Tahan Otot Lengan Dan Akurasi Memanah Pada Atlet Panahan. Med J IIm Kesehat Olahraga. 2019;18(2):79-85.

3. Humaid $\mathrm{H}$. Influence of arm muscle strength, draw length and archery technique on archery achievement. Asian Soc Sci. 2014;10(5):28.

4. Nusufi M. Kontibusi Daya Tahan Otot Lengan Dan Panjang Lengan Dengan Ketepatan Memanah Pada Atlet Panahan Pengprov Perpani Aceh Tahun 2015. J Ilmu Keolahragaan. 2016;5(1):1-25.

5. Gunawan G. Pengaruh Latihan Kekuatan Otot Lengan Terhadap Akurasi Tembakan Panahan Berbasis Aplikasi. SATRIA J "Sports Athl Teach Recreat Interdiscip Anal [Internet]. 2020;3(2):12-9. Available from: http://repository.upi.edu/id/eprint/21344

6. Wattimena Y F. Hubungan Motivasi Berprestasi dan Kecemasan Terhadap Prestasi Panahan Ronde Recurve Pada Atlet Panahan Di Indonesia. Motion. 2015;6(1).

7. Savitri N A A GI, Winaya N MI, Muliarta MI, Griadhi A putu I. Hubungan Persentase Lemak Tubuh Dan IMT Dengan Kekuatan Otot Genggam Pada Remaja Putri Usia 15-17 Tahun Di SMK Kesehatan Bali Medika DENPASAR. Maj IIm Fisioter Indones. 2020;6(3).

8. Vanagosi D K, Dewi P C P. Evaluasi Program Pembinaan Prestasi Cabang Olahraga Panahan Di Bali. J PENJAKORA. 2019;6(1):24-34.

9. Ilham M. Hubungan Konsentrasi Kekuatan Otot Lengan Dan Keseimbangan Tangan Dengan Ketepatan Memanah. J Sport Pedagog Progr Pascasarj Unsyiah. 2014;4(2).

10. Chattalia N V, Juhanna V I, Nugraha M H S, Wahyuni N. Hubungan Aktivitas Fisik Terhadap Kekuatan 
Genggaman dan Kecepatan Berjalan Pada Lansia Di Kelurahan Panje. Sport Fit J. 2020;8(3):205-11.

11. Munawar M, Hidayatullah MF, Kristiyanto A. Prediksi Prestasi Panahan Ronde Nasional Berdasarkan Daya Tahan Otot Lengan, Ketajaman Penglihatan, dan Kecemasan pada Atlet Pplp Panahan Jawa Tengah. Indones J Sport Sci. 2014;1(1).

12. Sheilani R. Hubungan Antara Kekuatan Otot Lengan,Kekuatan Otot tangan Dengan kemampuan chest Pass siswa Putra kelas VIII yang Mengikuti ekstrakurikuler Bola basket di Smp Negeri 1 Wates, Kulon ProgoYogyakarta. Fakultas IImu Keolahragaan Universitas Negeri Yogyakarta; 2013.

13. Pratama A. Perbandingan Durasi Menembak Dari Fase Holding ke Release Terhadap Prestasi Memanah Jarak 30 Meter Pada Cabang Olahraga Panahan. 2012.

14. Baskoro DA. Hubungan Kekuatan Otot Lengan, Vo2 Max dan Persepsi Kinestetik Terhadap Akurasi Tembakan Jarak 50 Meter. J Phys Educ Sport Heal Recreat. 2016;5(3):130-3.

15. Martiani M, Sugiyanto S, Pujianto D. Kontribusi Kekuatan Otot Lengan Dan Kekuatan Otot Punggung Terhadap Kemampuan Bantingan Pinggang Dalam Olahraga Gulat Atlet Pengda Pgsi Provinsi Bengkulu. Doctoral dissertation, Universitas Bengkulu. 2014.

16. Irmawati. Hubungan Kekuatan Otot lengan dan Daya Tahan Otot Lengan Terhadap Kemampuan Memanah Jarak 30 meter (Studi pada Atlet Panahan Perempuan NPC (National Paralympic Committee of Indonesia). 2020.

17. Risman GA. Kontribusi Kekuatan Otot Lengan, Keseimbangan, Dan Kecepatan Reaksi Terhadap Kemampuan Memanah Jarak 30 Meter Pada Atlet Panahan Lampung Ronde Nasional. 2016. 